\title{
Reworking Protocols in the Ophthalmology Department during the COVID-19 Crisis
}

\author{
Parul Chawla Gupta ${ }^{1}$ Praveen Kumar-M² Jagat Ram
}

Address for correspondence Jagat Ram, MS, FAMS, Department of Ophthalmology, Post Graduate Institute of Medical Education and Research, Chandigarh 160012, India (e-mail: drjagatram@gmail.com).

\begin{abstract}
Eye care professionals are susceptible to contract COVID-19 infection due to the presence of the virus in tears and conjunctival secretions and, also, partly due to the proximity required during ophthalmic examination. Although infrequent, ocular features include conjunctivitis (predominant), chemosis, follicles, itching, dry eye, and tearing. In this article, we have outlined salient safety recommendations at outpatient, inpatient and operation theater level for both patients as well as health

Keywords

- conjunctivitis

- triage

- ocular manifestations

- filtering face piece

- Aarogya Setu app care workers. Some of them being, creation of special triage areas at ophthalmology clinic for the screening of patients, things to be avoided at each level, procedures to manage appointments, examination room modifications, operation theater protocols, a suggestion for prioritizing cases, and finally airflow and hospital staff management. These suggestions, along with local hospital-specific modifications, will help us to go a long way in the battle against COVID-19.
\end{abstract}

\section{Introduction}

The world is facing an unprecedented challenge due to the Coronavirus crisis. In lines with other medical specialties, ophthalmic care has also undergone substantial modifications to tackle the Coronavirus disease (COVID-19) pandemic. ${ }^{1}$ In this brief review, we will be enumerating various changes which are imperative to be undertaken in these times and beyond. One of the initial alarms over COVID-19 was raised by a Chinese ophthalmologist, Li Wenliang, MD, who died after acquiring the virus from his own asymptomatic glaucoma clinic patient. ${ }^{2,3}$ Since the severe acute respiratory syndrome coronavirus 2 (SARS-CoV-2) is found in tears and conjunctival secretions (as evaluated by reverse transcriptase polymerase chain reaction [RT-PCR] in studies), ophthalmologists and optometrists, especially those on the frontlines, triaging patients may be susceptible to contract the infection; also, this is partly due to the close proximity the ophthalmic evaluation generally requires. ${ }^{4}$

\section{Ocular Manifestations of COVID-19}

Ophthalmic manifestations of COVID-19, although seen infrequently, should not be overlooked, and a high-index of suspicion should always be maintained as the occurrence of ocular transmission cannot be ignored. ${ }^{5}$ The majority of symptoms and signs include conjunctivitis/conjunctival congestion or hyperemia, follicles on the palpebral conjunctiva, increased tearing, photophobia, and preauricular lymphadenopathy. Nine out of 1099 patients (0.8\%)from 30 states in China had conjunctival congestion. ${ }^{6}$ As much as $31.6 \%$ of 38 Coronavirus patients in Hubei, China, reported conjunctival hyperemia, chemosis and epiphora as the main symptoms. ${ }^{7}$ However, only $16.7 \%$ of those affected had Coronavirus detected from both conjunctival and nasopharyngeal swabs. ${ }^{7}$ In the study by Xia et al, one patient had conjunctivitis and was also the only one to demonstrate Coronavirus in conjunctival swab by RT-PCR. ${ }^{8}$ Another patient showed bilateral follicular conjunctivitis 13 days after the onset of the viral 
illness and had positive RT-PCR from the conjunctiva, which remained positive till 17 days from the onset of the illness. ${ }^{9}$ A typical clinical presentations of the novel Coronavirus can occur, as was seen in five patients with nonresolving conjunctivitis, which was the only manifestation of the disease without any fever, cough or malaise. ${ }^{10}$ In one case report, keratoconjunctivitis (subepithelial infiltrates with overlying epithelial defects) was the first clinical presentation in a COVID-19 patient. ${ }^{11}$ Another 27-year-old patient presented with unilateral lid edema and conjunctival hyperemia which turned out to be COVID-19 with the manifestation of severe breathlessness later. ${ }^{12}$ A 63 -year-old man had pseudomembranous and hemorrhagic conjunctivitis associated with COVID-19 pneumonia which started as late as the 17th day of disease onset. ${ }^{13}$

Although ocular symptoms have relatively low-prevalence among COVID-19-infected patients, they have been shown to be associated with the disease severity amongst COVID-19 positive patients. ${ }^{14}$

\section{Triage Protocols for Outpatient Department}

Health care services are overwhelmed by this novel disease due to its extraordinary incidence of transmission, elevated susceptibility of the common man, advanced morbidity and mortality as compared with the influenza virus. Despite nationwide lockdowns, it has been difficult to contain this virus. ${ }^{10}$ So proper triage, as well as the screening of patients, is essential.

Entry points of the ophthalmology department ( - Fig. 1A) building need to be minimized, so that efficient monitoring of these points can be done with the limited resources. The entrance door should be kept open to avoid touching the knobs ( - Fig. 1C). The health care worker guarding the entrance should ask each patient about their travel history in the past 2 weeks(keeping in mind the incubation period of 1-14 days), ${ }^{15}$ history of contact with a COVID-19 positive patient or suspect, history of travel from a hotspot, ${ }^{16}$ history of symptoms like fever, malaise, cough, breathlessness and diarrhea, and lack of smell/taste. Fever should be assessed using noncontact thermal scanners. No attendants or children should be allowed accompanying the patient. Provision of taking throat swabs of suspected patients should be installed at the entrance ( - Fig. 1B). RT-PCR results are usually obtained after 8 to 10 hours. In suspected cases requiring emergency surgery, for example, penetrating eye injuries, facilities of GeneXpert system can be employed which gives test results in approximately 2 hours. Only one attendant may be allowed for dependent individuals. A mask should be provided to the patient if he or she is not already wearing one. After hand sterilization using hand sanitizers, the patient should be allowed entry in the building. A COVID-19 declaration and consent form ${ }^{17}$ should be signed by the patient using no-touch protocols. ${ }^{18}$ The health care worker should avoid touching the patient's documents and papers. The magazines and newspaper stands should be temporarily removed as they are potential fomites.

Social distancing of at least 1 to $1.5 \mathrm{~m}$ should be maintained in queues, and chairs should be blocked alternatively using bright-colored or contrast-colored tape ( - Fig. 1D). Appointments should be staggered by approximately 15 minutes, and it should be conveyed to the patients using
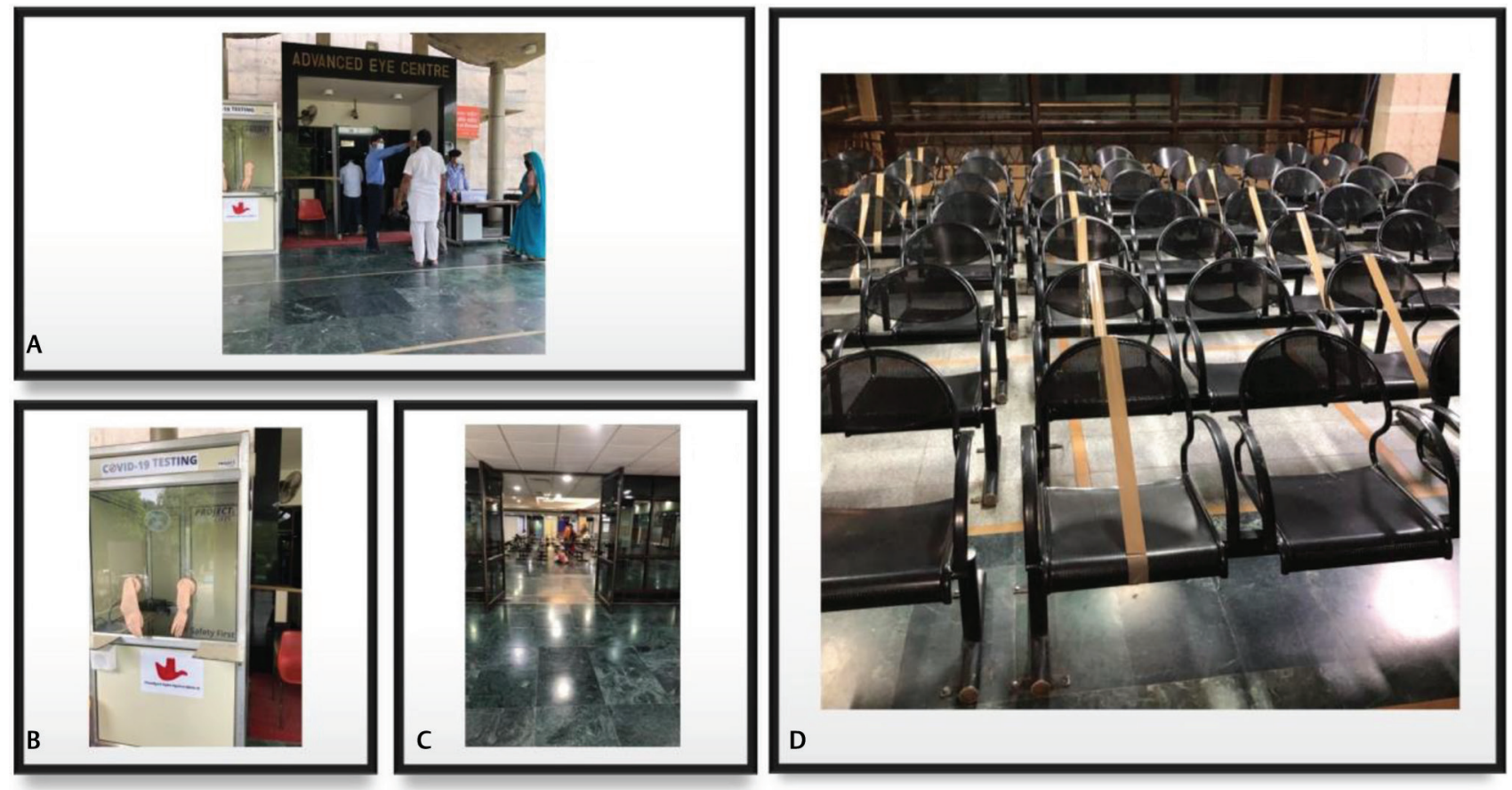

Fig. 1 (A) Single entry point of the ophthalmology department with thermal scanning and hand sanitizing of patients; (B) Provision of taking throat swabs of suspected patients installed with the facility of exchange of gloves after every patient; (C) Entrance door kept open to avoid touching the knobs; (D) Alternate chairs blocked with tape to maintain social distancing. 
short messaging service (SMS) or electronic mail (e-mail). Repeat appointments should be spaced out over 2 to 4 weeks if possible. Teleophthalmology and teleconsultations should be encouraged. ${ }^{12}$ Card or online payment should be preferred. Noncontact cash handling should be done using prongs. "Aarogya Setu app" (an application developed by the Government of India for tracking contacts of COVID-19 patient) installation, as mandated by the Government of India, should be checked. Lifts should be sanitized, and plastic cling film can be applied over the control buttons for the purpose of easy sanitization. Awareness posters should be put all around and at the entrance of the hospital ( - Fig. 2A-E) ${ }^{19}$

For air conditioning, windows/split air conditioners should be preferred with temperature and humidity settings as per norms. Central air conditioning supplying air through air handling units should be advised to run on maximum fresh air possible, and other standard recommendations should be followed. Exhaust fans should be installed to avoid recirculation of the air and create negative pressure, and their air should be ideally high-efficiency particulate air (HEPA)filtered..$^{20}$ Windows, if present, should be kept open. Breath shields made of plastic or old discarded X-rays should be fixed to slit lamps ( - Fig. 3B) and indirect ophthalmoscopes. Cotton buds should be used for lid eversions. Refractions and pupillary dilatations for fundus evaluation should be avoided. Near vision charts, Amsler grids, and keyboards should be kept covered with plastic cling films to ensure easy sanitization. Noncontact air-puff tonometry should not be done since it is an aerosol-generating procedure. ${ }^{16,17}$ Contact applanation tonometers can be used for recording intraocular pressures after which the tonometer tip can be washed with soap and water for at least 20 seconds and then airdried before using on the next patient. Since Coronavirus is present in tears, ${ }^{21}$ and $30 \%$ of affected individuals are asymptomatic, ${ }^{22}$ eye protection in the form of goggles or face shields along with filtering face-piece (FFP)-1/FFP-2 mask and gloves are imperative for all eye care providers ( - Fig. 3A). For examining a suspected or confirmed COVID-19 patient, full personal protective equipment (PPE) like N-95 mask, face shield, goggles, gloves, gowns, and shoe covers are required. Patients examined on the slit lamp must also mandatorily wear 3-ply face masks ( - Fig. 3C).

\section{Operation Theater Protocols}

In Wuhan, the most common emergency ophthalmic procedures included trabeculectomies/cataract surgeries for intraocular pressure control, emergency pars plana vitrectomies, suture removals, and treatment of preterm infants for retinopathy of prematurity. Ocular trauma was far less common because of people remaining mostly indoors. ${ }^{23}$

In the operation theater, donning and doffing should be done using sterile precautions. All staff should be trained to don, doff and in the disposal of PPE including masks (level 2 or $3 \mathrm{FFP}$, depending on the aerosol-generating risk level), eye goggles, long-sleeved waterproof gloves, gowns, caps, and shoe covers in dealing with suspected/confirmed COVID19 cases. ${ }^{24}$ For all other cases, it should be as per norms. A supervisor should be earmarked to help the eye care professionals and nursing staff carry out these procedures efficiently. Separate shortest routes must exist for suspected/ infected COVID-19 individuals. The COVID-19 operating area

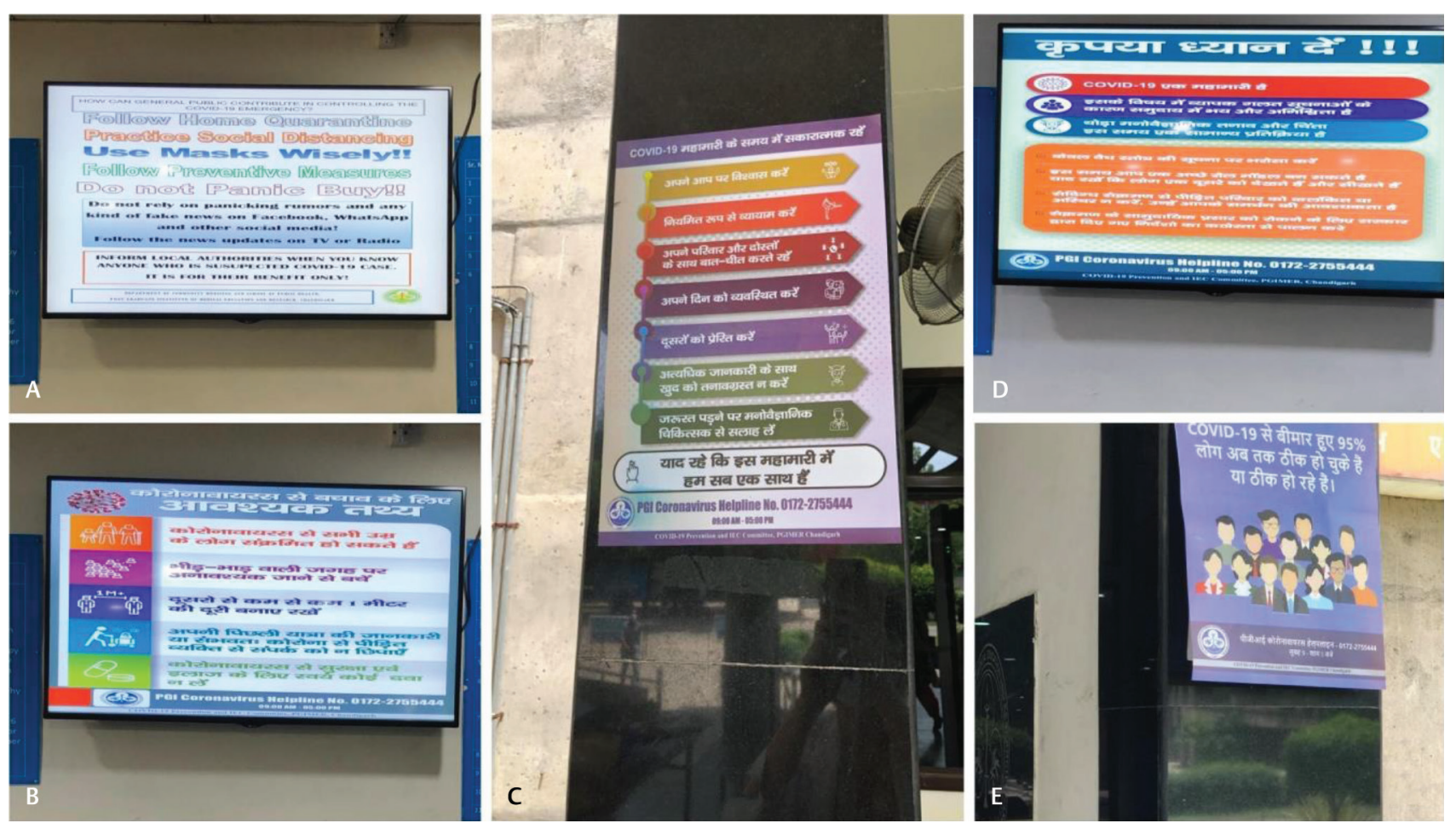

Fig. 2 (A-E) Awareness posters fixed at the entrance of the Advanced Eye Centre, Post Graduate Institute of Medical Education and Research, Chandigarh, India, in the English and Hindi languages along with rotational displays on the television screen. 

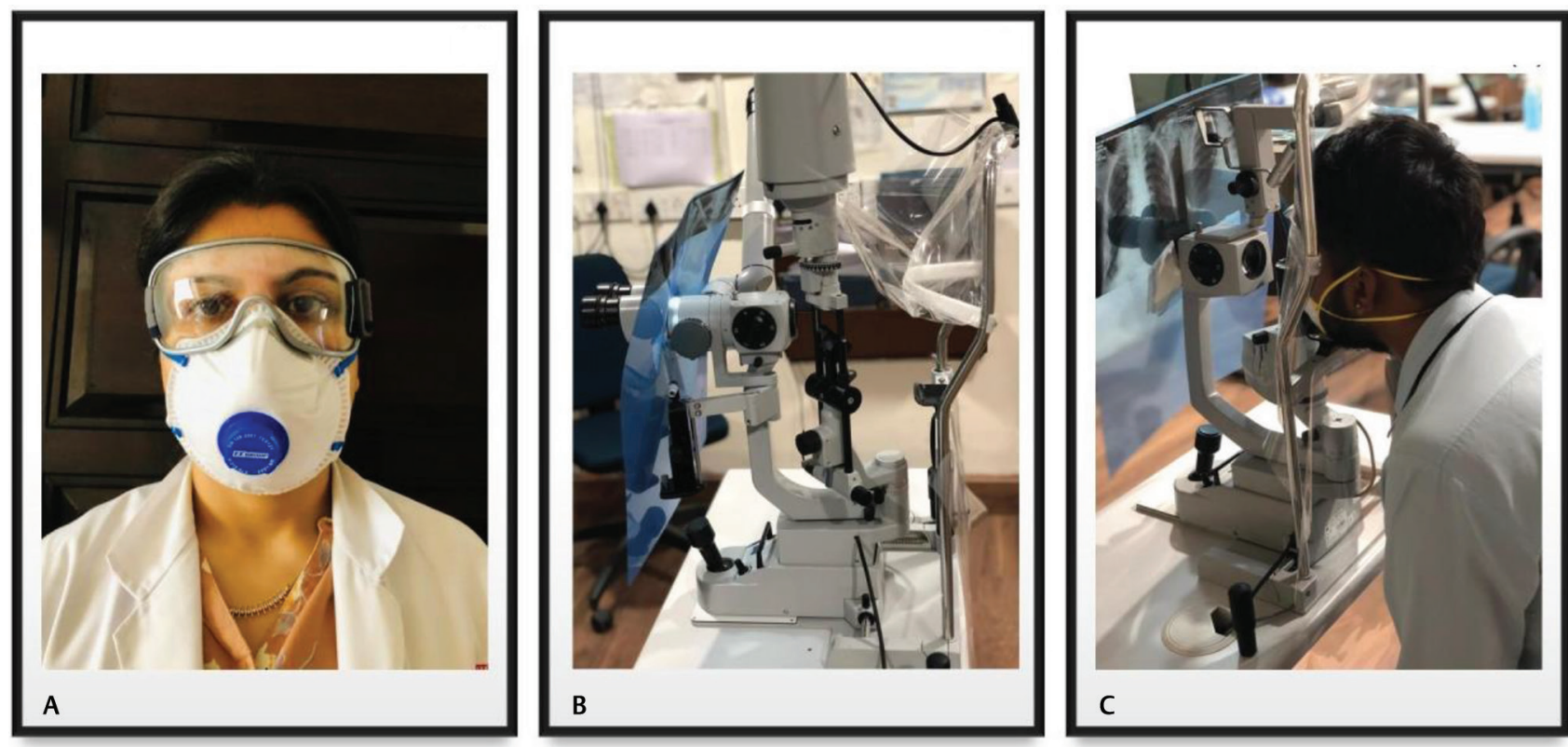

Fig. 3 (A) Eye care provider wearing a mask and protective goggles for examining patients on the slit lamp; (B) Breath shields made of clear plastic or old discarded X-rays fixed at the slit lamp; (C) Patients examined on the slit lamp mandatorily wearing a 3-ply facemask.

should be kept separate and preferably near the entrance of the theater complex. Operation theater doors must be kept closed after the entry of the patient, and the eye care personnel involved must leave only after the procedure is over. All clinical records should be kept outside the operating room. ${ }^{13}$ Negative pressure should be maintained in the operation theaters. ${ }^{25} \mathrm{~A}$ minimum of 12 exchanges of air/hour should be mandatory in the operation theaters to decrease the viral load. ${ }^{20}$ After every patient, cleaning of the operating room, table, microscope and machines should be done. A minimal number of residents and staff should be allowed when the surgery is going on. Refractive surgeries should be avoided, especially involving microkeratome use and laser ablation, as they lead to aerosol generation. Phacoemulsification is also an aerosol-generating procedure and should be avoided except in cases of children in the amblyogenic period with unilateral cataract or adults with lens-related glaucoma or uveitis which requires immediate lens extraction or in cases of traumatic cataract. ${ }^{17}$ Nasal endoscopy should also be avoided as it may promote sneezing, which is aerosolgenerating. ${ }^{26}$ Intravitreal injections should be given on a treat-and-extend basis, and Amsler charts and smartphone apps should be used for monitoring decline in vision. ${ }^{27}$

\section{Staff Management}

Biometric system of attendance should be suspended, and manual marking of attendance can be done. Staff should best staggered and called in 33 to $50 \%$ of total strength. Nursing and sanitation staff should be allowed to attend duty in nonformal clothes rather than uniforms to enable daily washing of clothes. Rings/bangles and watches use is to be discouraged. Hand-bag usage should also be discouraged. Loose-fitting, long-length garments should be avoided and well-fitted clothes should be preferred.
Hand hygiene etiquette should be strictly followed using povidone-iodine, combination of chlorhexidine and cetrimide or alcohol-based rubs. ${ }^{19}$ Staggered mealtimes should be adopted, and distanced seating at canteen's needs to be followed. The health care workers' interaction with patients or colleagues should be kept to a minimum. ${ }^{27}$ Disinfection of all surfaces and instruments should be performed using 70\% isopropyl alcohol, freshly prepared $1 \%$ sodium hypochlorite/ $1 \%$ bacillocid. ${ }^{17}$ There should be a mindful utilization of financial and human resources. Preservation of human and material resources are of paramount importance for the health care sector in the current scenario. Stressors related to the physical, mental and social well-being of ophthalmologists and other eye care staff from the patients, as well as personal safety concerns, should be addressed promptly. The morale of the staff should be kept high, and heightened vigilance is utmost in these testing times and beyond.

\section{Conclusion}

The ophthalmologist may be the first point of contact to evaluate COVID-19 patients, considering conjunctivitis as the initial clinical presentation. Stringent safety practices should be pursued, and triaging should be done for the most vulnerable patients, so that the best possible care can be provided to them with the utmost safety of the eye care professionals.

\section{Conflict of Interest}

None declared.

\section{References}

1 Siedlecki J, Brantl V, Schworm B, et al. COVID-19: ophthalmological aspects of the SARS-CoV 2 global pandemic. Klin Monbl Augenheilkd 2020;237(5):675:680 
2 Hu K, Patel J, Patel BC. Ophthalmic Manifestations Of Coronavirus (COVID-19). StatPearls Publishing;2020. Available at: http://www.ncbi.nlm.nih.gov/books/NBK556093/. Accessed May 10, 2020

3 Parrish RKII, Stewart MW, Duncan Powers SL. Ophthalmologists are more than eye doctors-in memoriam Li Wenliang. Am J Ophthalmol 2020;213:A1-A2

4 Seah I, Su X, Lingam G. Revisiting the dangers of the coronavirus in the ophthalmology practice. Eye (Lond) 2020. Doi: 10.1038/s41433-020-0790-7

5 Lu C-W, Liu X-F, Jia Z-F. 2019-nCoV transmission through the ocular surface must not be ignored. Lancet 2020;395(10224): e39

6 Guan W-J, Ni Z-Y, Hu Y, et al; China Medical Treatment Expert Group for Covid-19. Clinical Characteristics of Coronavirus Disease 2019 in China. N Engl J Med 2020;382(18):1708-1720

7 Wu P, Duan F, Luo C, et al. Characteristics of ocular findings of patients with Coronavirus disease 2019 (COVID-19) in Hubei province, China. JAMA Ophthalmol 2020. Doi: 10.1001/ jamaophthalmol.2020.1291

8 Xia J, Tong J, Liu M, Shen Y, Guo D. Evaluation of coronavirus in tears and conjunctival secretions of patients with SARS-CoV-2 infection. J Med Virol 2020. Doi: 10.1002/jmv.25725

9 Chen L, Liu M, Zhang Z, et al. Ocular manifestations of a hospitalised patient with confirmed 2019 novel coronavirus disease. Br J Ophthalmol 2020;104(6):748-751

10 Scalinci SZ, Trovato Battagliola E. Conjunctivitis can be the only presenting sign and symptom of COVID-19. IDCases 2020;20:e00774

11 Cheema M, Aghazadeh H, Nazarali S, et al. Keratoconjunctivitis as the initial medical presentation of the novel coronavirus disease 2019 (COVID-19). Can J Ophthalmol 2020. Doi: $10.1016 /$ j.jcjo.2020.03.003

12 Daruich A, Martin D, Bremond-Gignac D. Ocular manifestation as first sign of Coronavirus Disease 2019 (COVID-19): Interest of telemedicine during the pandemic context. J Fr Ophtalmol 2020;43(5):389-391

13 Navel V, Chiambaretta F, Dutheil F. Haemorrhagic conjunctivitis with pseudomembranous related to SARS-CoV-2. Am J Ophthalmol Case Rep 2020. Doi:10.1016/j.ajoc.2020.100735

14 Ulhaq ZS, Soraya GV. The prevalence of ophthalmic manifestations in COVID-19 and the diagnostic value of ocular tissue/fluid. Graefes Arch Clin Exp Ophthalmol 2020; 258(6):1351-1352

15 Guo Y-R, Cao Q-D, Hong Z-S, et al. The origin, transmission and clinical therapies on coronavirus disease 2019 (COVID-19) outbreak - an update on the status. Mil Med Res 2020;7(1):11

16 Lim LW, Yip LW, Tay HW, et al. Sustainable practice of ophthalmology during COVID-19: challenges and solutions. Graefes Arch Clin Exp Ophthalmol 2020. Doi: 10.1007/s00417020-04682-z
17 Sengupta S, Honavar SG, Sachdev MS, et al; Writing Committee on behalf of the All India Ophthalmological Society - Indian Journal of Ophthalmology Expert Group for COVID-19 Practice Guidelines; Composition of the All India Ophthalmological Society - Indian Journal of Ophthalmology Expert Group for COVID-19 Practice Guidelines includes the Writing Committee (as listed) and the following members (in alphabetical order by the first name). All India Ophthalmological Society - Indian Journal of Ophthalmology consensus statement on preferred practices during the COVID-19 pandemic. Indian J Ophthalmol 2020;68(5):711-724

18 Lai TH, Tang EWH, Chau SKY, Fung KSC, Li KK. Stepping up infection control measures in ophthalmology during the novel coronavirus outbreak: an experience from Hong Kong. Graefes Arch Clin Exp Ophthalmol 2020;258(5):1049-1055

19 Khanna RC, Honavar SG. All eyes on Coronavirus-What do we need to know as ophthalmologists. Indian J Ophthalmol 2020; 68(4):549-553

20 COVID-19 Guidance Document for Air Conditioning and Ventilation. AICTE- India.org. Available at: https://www. aicte-india.org/. Accessed May 16, 2020

21 Loon S-C, Teoh SCB, Oon LL, et al. The severe acute respiratory syndrome coronavirus in tears. Br J Ophthalmol 2004;88(7): 861-863

22 Nishiura H, Kobayashi T, Miyama T, et al. Estimation of the asymptomatic ratio of novel coronavirus infections (COVID-19) Int J Infect Dis 2020;94:154-155

23 Du H, Zhang M, Zhang H, Sun X. Practical experience on emergency ophthalmic surgery during the prevalence of COVID19. Graefes Arch Clin Exp Ophthalmol 2020. Doi: 10.1007/ s00417-020-04692-X

24 Coccolini F, Perrone G, Chiarugi M, et al. Surgery in COVID19 patients: operational directives. World J Emerg Surg 2020;15(1):25

25 Ti LK, Ang LS, Foong TW, Ng BSW. What we do when a COVID19 patient needs an operation: operating room preparation and guidance. Can J Anaesth 2020;67(6):756-758

26 Tran K, Cimon K, Severn M, Pessoa-Silva CL, Conly J. Aerosol generating procedures and risk of transmission of acute respiratory infections to healthcare workers: a systematic review. PLoS One 2012;7(4):e35797

27 Korobelnik J-F, Loewenstein A, Eldem B, et al. Guidance for antiVEGF intravitreal injections during the COVID-19 pandemic. Graefes Arch Clin Exp Ophthalmol 2020;258(6):1149-1156 